\title{
Correlations between cerebral blood flow variations and clinical parameters in temporal lobe epilepsy: an interictal study
}

\author{
J VALMIER, J TOUCHON, P DAURES, ${ }^{*}$ M ZANCA, M BALDY-MOULINIER \\ From the Service d'EEG et d'Explorations Fonctionnelles du Système Nerveux, Centre Médical Gui de Chauliac, \\ and the Service d'Informatique Médicale, Hôpital Lapeyronie, 34000 Montpellier, France
}

SUMMARY Regional cerebral blood flow (rCBF) measurements were determined by the intravenous Xenon 133 technique in 80 patients suffering from temporal lobe epilepsy. All the patients had a normal CT scan. Three subgroups were differentiated, according to EEG and all-night polygraphic recordings: temporal lobe epilepsy with left $(\mathrm{N}=25)$ or right $(\mathrm{N}=25) \mathrm{EEG}$ epileptic abnormalities and temporal lobe epilepsy with EEG abnormalities in both temporal regions with asynchronous occurrence $(n=30)$. In comparison with a control group $(n=20)$, there was $(1)$ a marked reduction of blood flow in the temporal region corresponding to the site of the epileptic focus and (2) a reduction in blood flow in distant brain areas and the contralateral hemisphere. The rCBF decrease was highly correlated $(\mathrm{p}<0.001)$ with the disease severity (taking into acount the complex partial seizure frequency and the number of secondary generalised seizures). Differences were found in the rCBF decrease between left and right temporal lobe epilepsy.

Interictal investigations in partial epilepsy have demonstrated a reduced blood flow in the epileptogenic region of the brain. Such haemodynamic alterations were detected in patients with temporal lobe epilepsy by using various techniques for determining regional cerebral blood flow (rCBF) including 133 Xenon two dimensional clearance technique,$^{1-3}$ single photon emission computed tomography (SPECT) ${ }^{4}$ and positron emission tomography (PET). ${ }^{5}$ Focal reductions of metabolism also have been found in temporal lobe epilepsy. ${ }^{6-13}$ The localisation of both hypoperfusion and hypometabolism corresponded to the epileptogenic focus. Until now, the rCBF and metabolism decrease have been attributed to cerebral hypoactivity, but the exact mechanism remains unclear.

Of physiological interest is the fact that the reduction of flow may extend to areas distant from the EEG focus. ${ }^{14}$ Therefore, using the two dimensional Xenon 133 method which permits cortical haemodynamic measurements, the aim of this study was:

Address for reprint requests: Dr Jean Valmier, Service d'EEG et d'Explorations Fonctionnelles du Système Nerveux, Centre Médical Gui de Chauliac, 34059 Montpellier, France.

Received 14 October 1986 and in revised form 28 January 1987. Accepted 30 January 1987
(1) to confirm the previous preliminary results con cerning functional haemodynamic impairment at distance for the EEG epileptic focus in a larger popu lation of epileptic patients with complex partial seico zures $(\mathrm{N}=80),(2)$ to determine, using multivariate analysis if some clinical parameters are related to these decreases of rCBF.

\section{Subjects and methods}

Eighty epileptic patients (the temporal lobe epilepsy group) ( 32 females, 48 males, mean age $=27 \cdot 18$; range $9-59$ years) underwent rCBF measurements. All but three of the patients were right-handed. None of them had any abnormality on repeated neurological examination and CT scan. All of them had complex partial seizures in accordance with the international classification. ${ }^{15} 16$ Aetiology was unknown in most of the cases, 15 patients had febrile convulsions during childhood, eight had a perinatal insult. A history of epilepsy was found in the families of three patients. According to the new international classification ${ }^{17}$ and the fact that all the CT scans were normal, 57 subjects had idiopathic epilepsy.

Four clinical criteria were considered for each subject: age, age at the onset of epilepsy, duration of the disease and severity of the epilepsy. This last parameter was evaluated by a clinical index ("severity index" (SI)) taking into account the frequency of the complex partial seizures (CPS) and the number of secondary generalised tonic-clonic seizures (SGS) by using the following scoring system: (1) one CPS a year; 
(2) one CPS quarterly; (3) one CPS monthly; (4) one CPS biweekly; (5) one CPS weekly; (6) one CPS daily. The number of secondary generalised tonic-clonic seizures was scored (1) for less than five SGS; (2) for a score between five and 10 SGS; (3) for a score between 10 and 20 SGS; (4) for more than 20 SGS. None of them had CPS or SGS during the 48 hour period prior to rCBF measurements. CPS frequency and SGS number were monitored during 2 weeks hospitalisation before rCBF measurements and by a home seizure book, over a minimum of 6 months (because some of the patients had epilepsy which began only 6 months before). Of 100 selected epileptic patients, 20 were excluded because their SI was indeterminable.

The 80 patients were divided into three subgroups according to the EEG findings of repeated standard day time EEG and all night polygraphic recordings: (a) left temporal group $(\mathrm{N}=25)$ with focal interictal epileptiform discharges in the left temporal region, (b) right temporal group $(\mathrm{N}=25)$ with focal interictal epileptiform discharges in the right temporal region, (c) bitemporal group $(\mathbf{N}=30$ ) with unstable focal epileptiform discharges found in both temporal regions either alternately or simultaneously but with an asynchronism or an asymmetry between the right and left sides.

Antiepileptic therapy remained unmodified during the months preceding the study. Treatments were different between patients but not between groups. All the patients were treated by monotherapy (carbamazepine or sodium valproate) or polytherapy with a combination of phenobarbitone and carbamazepine or phenytoin and sodium valproate. Six patients had tritherapy with carbamazepine, phenytoin and phenobarbitone at the time of rCBF measurements. The plasma levels of antiepileptic drugs ranged from 16 to $40 \mu \mathrm{mol} / 1$ for carbamazepine, 350 to $840 \mu \mathrm{mol} / 1$ for sodium valproate, 40 to $80 \mathrm{~mol} / \mathrm{l}$ for phenytoin and 65 to $170 \mathrm{~mol} / 1$ for phenobarbitone.

Twenty normal volunteers having no history of neurological disease, showing no signs of CNS impairment and receiving no drugs were examined by IV. 133 xenon clearance technique for the determination of rCBF control values. Mean age of normal subjects was 26.75 (range 21-39 years). Eight were females and 12 males.

The EEG was recorded with conventional scalp electrodes prior to or at the time of rCBF measurements. All the patients were also submitted to two or more all night sleep polygraphic recordings in order to establish the localisation and the fixity of the epileptic focus (production of spikes, spikes and waves or sharp waves). It is considered that such an examination gives indications concerning the lateralisation of the epileptic focus similar to the depth EEG recordings when lateral EEG abnormalities are found during waking, NREM sleep and REM sleep. ${ }^{18} 19$

Clearance of 133 xenon following intravenous injection was used to perform rCBF measurements (Mecaserto system). The tracer $(15 \mathrm{mCi})$ was injected intravenously in a bolus. At the time of measurements, the patient was isolated in a quiet and darkened room. The subject was required to lie down and to refrain from talking. Arterial blood pressure and $\mathrm{CO}_{2}$ arterial partial pressure $\left(\mathrm{PaCO}_{2}\right)$ were performed during and after $\mathrm{rCBF}$ measurements. $\mathrm{rCBF}$ was computed by a two compartmental analysis of the clearance curve and with a correction for xenon recirculation based on the endtidal tracer concentration..$^{21}$ The study of rCBF was lim- ited to $F 1$ derived from the initial slope of the clearance curve and considered as grey-matter flow. Reliability of the CBF values was controlled twice or more in some controls and several patients by repeating the measurements in similar conditions. Thirteen sodium iodide crystal scintillation detectors were placed symmetrically over each hemisphere. Two regions of interest were selected on each hemisphere: the temporal region (T) (four detectors) and the extratemporal region (extraT) (nine detectors). Average CBF values for extraT region (extraTCBF) and for $T$ region (TCBF) were calculated from individual measurements. In order to eliminate the age factor in $\mathrm{rCBF}$ values, especially with regard to young patients ( $<15$ years), $2-27$ an $\mathrm{rCBF}$ decrease index (DI) was calculated for each subject as follows:

$$
\mathrm{DI}=\frac{\text { epileptic } \mathrm{rCBF}}{\text { age-matched normal volunteers rCBF }}
$$

where epileptic $\mathrm{rCBF}$ represents the $\mathrm{CBF}$ in the region of interest $r$ of the epileptic patient, and age-matched normal volunteers $\mathrm{CBF}$ represents the theoretical $\mathrm{CBF}$ value in the region of interest $r$ of an age-matched control patient.

For the different regions of interest, the theoretical rCBF value of an age-matched controls patient is given by the following equations:

Right temporal CBF $=(157.453 \times$ age -0.3074$)+3.8$

Left temporal CBF $=(157.453 \times$ age -0.3074$)+2.8$

Right extraT CBF $=(157.453 \times$ age -0.3074$)+5.3$

Left extraT CBF $=(157.453 \times$ age -0.3074$)+4.3$

These equations were derived from rCBF study performed on 40 control subjects ( 14 females, 26 males, age $=30.75-$ range: 13-61 years). Therefore, the equation (DI) conveys the rCBF decrease of each epileptic patient compared with an age-matched control, thus eliminating the age factor.

The populations were normally distributed $\left(\chi^{2}\right.$ test) and their variance values were comparable (Fischer test, $\mathrm{p}<0.01$ ). The different groups were compared by the Student $t$ test. Differences were not considered significant if the level of confidence did not exceed $95 \%$. Because it was not possible to examine the hierarchy between the clinical parameters contributing to the rCBF decrease on the basis of a single-factor analysis, multivariate analysis, which shows the reciprocal relationships between factors, was used. We tried to explain some of the quantitative variables (rCBF variations) for each epileptic localisation by other quantitative variables (clinical data) by showing a hierarchy in the occurrence of these variables. For this purpose, we used a stepwise method which associated a forward selection and a backward elimination. The test used to hierarchically select the variables was the Fisher Snedecor test (the multiple correlation coefficient was supplied) (In all these studies $:=1 \%$ for Ho elimination and: $5 \%$ for Ho acceptance).

\section{Results}

\section{rCBF decrease pattern of temporal lobe epilepsy}

$(n=80)$

For the 20 normal volunteers, the mean right and left extra TCBF values were respectively $63.88 \pm$ $9.6 \mathrm{ml} / 100 \mathrm{~g} / \mathrm{min}$ and $62.94 \pm 9.3 \mathrm{ml} / 100 \mathrm{~g} / \mathrm{min}$. The mean right TCBF was $62.54 \pm 8.4 \mathrm{ml} / 100 \mathrm{~g} / \mathrm{min}$ and 


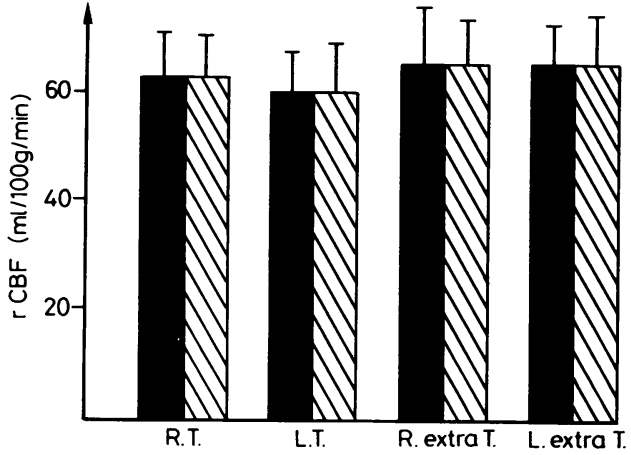

Fig 1 Reproducibility of $r C B F$ determination in six normal subjects. Black = first measurement $;$ grey $=$ second measurement; $R T=$ right temporal region; $L T=$ left temporal region; $R$ extraT $=$ right extratemporal region; $L$ extraT $=$ left extratemporal region.

mean left TCBF was $61 \cdot 14 \pm 8 \cdot 3 \mathrm{ml} / 100 \mathrm{~g} / \mathrm{min}$. There was no difference between homo- and contralateral rCBF values. Figure 1 shows the reproducibility in the right and left TCBF and extraTCBF values for investigations repeated under the same conditions. The rCBF decrease index (DI) was $1.01 \pm 0.13$ for each region of interest (table 1). This result proves the validity of the DI.

The overall results of patients with temporal lobe epilepsy showed a rCBF decrease for the TCBF ( $p<$ $0.001)$ and extra TCBF (p < 0.01) (table 1). rCBF in the temporal group with left EEG epileptic focus was characterised by a global decrease $(-14 \%)$, which was greater in the left temporal region $(-20 \%)$ (table 1). rCBF in the temporal group with right EEG epileptic focus showed a reduction of blood flow only in the right temporal region $(-10 \%)$ as compared with the control group (table 1). rCBF in the temporal group with bilateral and asynchronous or unilateral and alternative EEG epileptic focus had a rCBF decrease with the extraT DI $(p<0.05)$ and the T DI $(\mathrm{p}<0.01)$ (table 1).

The decrease index values (DI) for the temporal epileptic regions $(\mathrm{p}<0.02)$, the ipsilateral extratemporal regions $(\mathrm{p}<0.02)$, the contralateral epileptic regions $(p<0.05)$ and the contralateral extratemporal regions $(p<0.05)$ were significantly different between right and left temporal lobe epilepsy groups.

\section{Correlation between $\mathrm{CCBF}$ decrease and clinical parameters}

For the temporal group $(\mathrm{n}=80$, mean age $=27 \cdot 18$, range 9-59 years), with no consideration of the site of the epileptic focus, the age at the onset of the disease was $16.62 \pm 10.59$ years, the duration of the disease $10.57 \pm 9.06$ years, and the severity index $5.44 \pm 2 \cdot 4$. The correlations between the four clinical parameters and the four regional DIs are shown in table 2 . Thळ severity index was negatively correlated with thథ rCBF values $(p<0.001)$. The age of the patient, the를 age at the onset of the epilepsy and the duration of the disease showed no significant correlations. TP improve the validity of the severity index (SI) varis

Table 1 Decrease index values of the right (RTDI) and left (LTDI) T regions, of the right ( $R$ extraTDI) and left (L extra TDI) extraT regions for the five groups: control group (CG), temporal lobe epilepsy group (TLE) with left (LTLE), right (RTLE) and bitemporal (BiTTLE) EEG focus

\begin{tabular}{|c|c|c|c|c|}
\hline & $R T D I$ & $L T D I$ & RextraTDI & LextraTDI \\
\hline $\begin{array}{l}\text { CG } \\
\text { TLEG } \\
\text { LTLEG } \\
\text { RTLEG } \\
\text { BiTLEG }\end{array}$ & $\begin{array}{l}1.01 \pm 0.14 \\
0.91 \pm 0.14 \ddagger \\
0.88 \pm 0.15 \dagger \\
0.91 \pm 0.15^{*} \\
0.91 \pm 0.14 \dagger\end{array}$ & $\begin{array}{l}1.01 \pm 0.12 \\
0.89 \pm 0.14 \ddagger \\
0.82 \pm 0.13^{\ddagger} \\
0.97 \pm 0.14 \\
0.88 \pm 0.14 \dagger\end{array}$ & $\begin{array}{l}1.01 \pm 0.13 \\
0.94 \pm 0.15 \dagger \\
0.90 \pm 0.15 \dagger \\
0.96 \pm 0.14 \\
0.93 \pm 0.16^{*}\end{array}$ & $\begin{array}{l}1.01 \pm 0.12 \\
0.94 \pm 0.14 \dagger \\
0.89 \pm 0.16 \dagger \\
1.00 \pm 0.14 \\
0.93 \pm 0.13^{*}\end{array}$ \\
\hline
\end{tabular}

${ }^{*} \mathrm{p}<0.05 ; \mathrm{tp}<0.01 ; \ddagger \mathrm{p}<0.001$.

Table 2 Correlation between the four clinical parameters and decrease index of the right (RTEMPORAL) and left $(L T E M P O R A L)$ temporal regions and of the right ( $R$ extraT) and left ( $L$ extraT) extraT regions in the temporal lobe epilepsy group $(n=80)$

\begin{tabular}{|c|c|c|c|c|c|c|c|}
\hline & \multirow[b]{2}{*}{$N$} & \multicolumn{3}{|c|}{ Sex } & \multirow{2}{*}{$\begin{array}{l}\text { Onset } \\
\text { of the disease (years) }\end{array}$} & \multirow{2}{*}{$\begin{array}{l}\text { Duration } \\
\text { of the disease (years) }\end{array}$} & \multirow[b]{2}{*}{ Severity index } \\
\hline & & $\bar{M}$ & $F$ & Age (years) & & & \\
\hline $\begin{array}{l}\text { LTLEG } \\
\text { RTLEG } \\
\text { BiTLEG }\end{array}$ & $\begin{array}{l}25 \\
25 \\
30\end{array}$ & $\begin{array}{l}14 \\
13 \\
21\end{array}$ & $\begin{array}{r}11 \\
12 \\
9\end{array}$ & $\begin{array}{l}30.48 \pm 11.32 \\
28.48 \pm 10.8 \\
23.48 \pm 7.92\end{array}$ & $\begin{array}{l}17.65 \pm 14.27 \\
18.68 \pm 9.05 \\
14.03 \pm 7.9\end{array}$ & $\begin{array}{r}12.87 \pm 9.95 \\
9.8 \pm 0.08 \\
9.41 \pm 8.24\end{array}$ & $\begin{array}{l}* 6.26 \pm 1.98 \\
4.72 \pm 2.65 \\
5.41 \pm 2.36\end{array}$ \\
\hline
\end{tabular}

${ }^{*} p<0.05$ between RTLEG and LTLEG. 


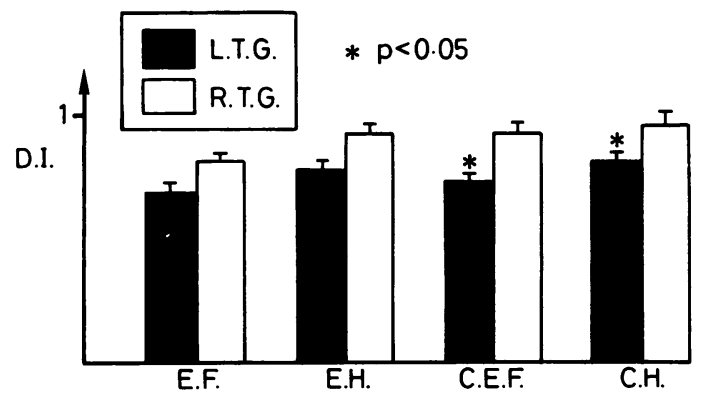

Fig 2 Comparison of severity index in matched left and right temporal epileptic groups. LTG = left temporal group $(n=13) . R T G=$ right temporal group $(N=9)$. The $C B F$ decrease index values $(D I)$ are significantly different in the contralateral temporal (CEF) and contralateral extratemporal $(\mathrm{CH})$ regions and not in the temporal epileptic $(E F)$ and the ipsilateral extratemporal (EH) regions.

able, SI monotonic transformations (square roots, logarithm) were performed. The results were unchanged.

\section{Influence of the EEG focus lateralisation on the $\mathrm{rCBF}$} decrease

The intensity and the spatial extent of the hypoperfusion were found to be different between the three subgroups (table 1). Furthermore, their SI ( $<<0.05)$ (table 2) and the localisation of their EEG epileptic focus were also different. In order to understand the respective influence of the lateralisation of the EEG epileptic focus and of the severity of the illness upon the rCBF decrease pattern, two populations were selected and compared, one with a stable right EEG epileptic focus and the other with a stable left epileptic focus, both presenting a matched severity index. Whereas the rCBF determinations in the $T$ and extraT regions corresponding to the EEG epileptic focus showed equivalent values, the contralateral hemispheric $\mathrm{CBF}$ to the epileptic focus was significantly decreased $(p<0.05)$ in the SI matched left temporal group as compared with the SI matched right temporal group (fig 2).

It is known that anticonvulsant drugs may decrease cerebral metabolism ${ }^{13}$ and perhaps CBF. Therefore it was required that the two groups (with a matched severity index) receive equivalent drug therapy. Two sets of parameters were analysed and compared; the duration of the treatment (years) and the taking of polytherapy, using the following score: (1) monotherapy (2) bitherapy (3) tritherapy. No difference was found between these two groups.

\section{Discussion}

$r C B F$ decrease was observed in areas distant from the EEG epileptic focus

This study shows: (1) a marked reduction occurs in blood flow in the temporal region corresponding to the site of a stable EEG epileptic focus, (2) rCBF decreases in cortical areas at a distance from the epileptic focus.

The cortical hypoperfusion corresponding to the EEG epileptic focus, in the interictal state, has been confirmed by the other rCBF two dimensional methods. ${ }^{128-30}$ Tridimensional methods such as PET and SPECT, ${ }^{4}$ (which provide information concerning cortical and deep rCBF abnormalities) have shown that hypoperfusion often extends to the mesial temporal areas.

The existence of a rCBF decrease at a distance from the epileptic focus confirms preliminary studies. ${ }^{14}$ The hypoperfusion in distant brain areas was always less than in the temporal epileptic region.

\section{Clinical parameters were correlated with $\mathrm{rCBF}$ decrease}

One of the remarkable findings in this study was the demonstration of the existence of a strongly significant negative correlation between the EEG epileptic focus, $\mathrm{CBF}$, and the illness severity parameters, regardless of the epileptic focus localisation. This correlation exists as much for the TCBF reduction $(p<$ $0.01)$ as for the extra TCBF reduction $(p<0.01)$. To our knowledge, this relationship has not been previously reported.

If the rCBF decrease depends upon a microscopic pathological process, often invisible with CT scan, sometimes visible with MRI, ${ }^{31}$ it also implies a functional process. The mechanisms of this must still be specified. The hyperaemia in the region of the EEG epileptic focus characterised by an rCBF decrease during the interictal period, ${ }^{72-35}$ is accompanied by normal vascular functional reactivity of the epileptogenic areas to variations of $\mathrm{PaCO}_{2}{ }^{36}$ This underlines the functional aspect of the $\mathrm{rCBF}$ decrease in the region of the EEG epileptic focus. Furthermore, surgical removal of focal epileptic lesions may be followed by normalisation of the distant hypoperfused cerebral areas. ${ }^{37}$

The proof of a rCBF decrease in areas distant from the EEG focus on the one hand and of a negative correlation between this hypoperfusion and clinical parameters on the other hand represents an additional argument for the existence of functional mechanisms in relation to the $\mathrm{rCBF}$ pattern of temporal lobe epilepsy.

Does a functional haemodynamic asymmetry exist between right and left temporal epileptic regions? Other issues raised by the present study are the particular features of the distribution pattern of rCBF in each subgroup. The flow reduction at a distance from the EEG focus is larger and more intense in patients 
with a left-sided temporal focus than in those with a right temporal focus. On the one hand the temporal lobe epilepsy group showed a rCBF decrease mostly correlated with the severity of the disease; on the other hand the left temporal lobe epilepsy group had a severity index greater than that of the right temporal lobe epilepsy group. This result raises the question of the respective role of the illness severity on the one hand and of the EEG epileptic focus lateralisation on the other, in determining the rCBF pattern difference between the left and right temporal lobe epilepsy group. In order to answer this question, two matched populations receiving equivalent drug therapy, one with a stable right EEG epileptic focus, and the other one with a stable left EEG epileptic focus were selected and compared. The results suggest that the lateralisation of the epileptic focus plays an important part in the haemodynamic decrease of the contralateral region. The rCBF decrease seemed larger when the EEG epileptic focus was in the left temporal region than in the right temporal region.

In conclusion, the proof of a correlation between the illness severity and the rCBF decrease opens up a new field of haemodynamic investigations in temporal lobe epilepsy. From a physiopathological point of view, it would be interesting to determine if any correlation exists between the rCBF decrease and other clinical, aetiological, pharmacological and psychological data. Furthermore, it would be interesting to investigate with three dimensional methods if such rCBF abnormalities are also present in deep cerebral regions at a distance from the EEG epileptic focus, and whether these correlate with some clinical parameters. Finally, the study of the haemodynamic asymmetries existing as a function of the EEG epileptic focus lateralisation seems to be a good investigative tool for certain mechanisms that underlie the cerebral functional activity and the hemispheric specialisations.

\section{References}

1 Lavy S, Melamed E, Portnoy Z, Carmon A. Interictal regional cerebral blood fiow in patients with partial seizures. Neurology 1976;26:418-22.

2 Rosadini G, Ferrillo F, Rodriguez G, Sannita WG, Arvigo F. rCBF and quantitiative EEG correlations in epileptic patients. In: Baldy-Moulinier M, Ingvar DH, Meldrum BS, eds. Cerebral Blood Flow Metabolism and Epilepsy. London: John Libbey Eurotext, 1983:26-32.

3 Touchon J, Valmier J, Baldy-Moulinier M. Regional cerebral blood flow in temporal lobe epilepsy inter-ictal studies. In: Baldy-Moulinier M, Ingvar DH, Meldrum BS, eds. Cerebral Blood Flow, Metabolism and Epilepsy. London: John Libbey Eurotext, 1983:33-38.

4 Bonte FJ, Stokely EM, Devous MD, Homan RW. Single photon tomographic study of regional cerebral blood flow in epilepsy. A preliminary report. Arch of Neurology 1983;80:267-70.

5 Feindel W, Gloor P, Yamamoto L, Gotman J, Shimizu H, Ochs R. Correlation of EEG and topographic cerebral blood flow in epilepsy by positron emission tomography. In: Akimoto H, Kazamatsuki H, Seino M, Warda A, eds. Advances in Epileptology. XIIIth Epilepsy International Symposium. New York: Raven Press, 1982.

6 Kuhl DE. Engel J Jr, Phelps ME, Selin C. Epileptic patterns of focal cerebral metabolism and perfusion in human, determined by emission computed tomography of FDG and ${ }^{13} \mathrm{NH}_{3}$. Ann Neurol 1980;8:348-60.

7 Newmark ME, Theodore W, De La Paz R. Positron emission computed tomography in refraction complex partial seizures. Ann Neurol 1981;10:73-74.

8 Engel J Jr, Brown NJ, Kuhl DE. Phelps ME, Mazziotta JC, Crandall PH. Pathological findings underlying focal temporal lobe hypometabolism in partial epilepsy. Ann Neurol 1982;12:518-28.

9 Yamamoto UL, Ochs R, Gloor P, et al. Patterns of rCBF and focal energy metabolic changes in relation to electroencephalographic abnormality in the inter-ictal phase of partial epilepsy. In: Baldy-Moulinier M, Ingvar DH, Meldrum BS, eds. Cerebral Blood Flow, Metabolism and Epilepsy. London: John Libbey Eurotext, 1983:51-62.

10 Sanabria E, Chauvel P, Askienasy S, et al. Single photon emission computed tomography (SPECT) using 123 I-Isopropropyl iodo amphetamine (IAMP) in partial epilepsy. In: BaldyMoulinier M, Ingvar DH, Meldrum BS, eds. London: John Libbey Eurotext, 1983:82-87.

11 Bernardi S, Gallhofer B, Trimble MR, Frackowiack RS, Wise $\mathrm{RJ}$, Jones T. An inter-ictal study of partial epilepsy using the oxygen-15 inhalation technique and positron emission tomography with special reference to psychosis. In: Baldy-Moulinier M, Ingvar DH, Meldrum BS, eds. London: John Libbey Eurotext, 1983:40-44.

12 Engel J Jr, Kuhl DE, Phelps ME, Mazziotta JC. Interictal cerebral glucose metabolism in partial epilepsy and its relation to EEG changes. Ann Neurol 1982;12:510-7.

13 Théodore WH, Newmark ME, Sato S, et al. F-Fluorodeoxyglucose positron emission tomography in refractory complex partial seizures. Ann Neurol 1983;14:429-38.

14 Baldy-Moulinier M, Valmier J, Touchon J, Billiard M, Besset A, Cadilhac J. Débits cérébraux régionaux diminués en période intercritique dans l'épilepsie du lobe temporal. Rev Neurol (Paris) 1985;141:18-27.

15 Gastaut H. Clinical and electroencephalographical classification of epileptic seizures. Epilepsia 1970;11:102-13.

16 Commission on Classification and Terminology of the International League Against Epilepsy. Epilepsia 1981;22:489-501.

17 Commission on Classification and Terminology of the International League Against Epilepsy. Epilepsia 1985;26:268-78.

18 Lieb JF, Joseph JP, Engel J Jr, Walker J. Paul H. Sleep state and seizure foci related to depth spike activity in patients with temporal lobe epilepsy. Electroenceph Clin Neurophysiol 1980;49:538-57.

19 Mountplaisir J, Laverdière M, Saint Hillaire JM. Sleep and focal epilepsy: Contribution of depth recording. In: Sterman MB, Shouse MN, Passouant P, eds. Sleep and Epilepsy. Academic Press, 1982:301-14.

20 Meric P, Seylaz J, Correze JL, Luft A, Mamo H. Measurements of regional blood flow by intravenous injection of 133 xenon. Med Prog Technol 1979;6:53-63.

21 Seylaz J, Meric P, Correze JL, Luft A, Mamo M. Analytical problems associated with the non invasive measurements of cerebral blood flow in cerebrovascular disease. Med Biol Eng Comput 1980;18:39-47.

22 Kety SS. Human cerebral blood flow and oxygen consumption as related to aging. J Chronic Dis 1956;3:478-86.

23 Gottstein U, Held K. Effects of aging on cerebral circulation and metabolism in man. Acta Neurol Scand 1979;Suppl 72, 60:54-5.

24 Naritomi H, Meyer JS, Sakai F. Yamaguchi F, Shaw T. Effects of advancing age on regional cerebral blood flow. Zrch Neurol 1979;38:410-8. 
25 Shaw T, Meyer JS, Mortel K, Cutala M, Sakai F, Yamaguchi F. Effects of normal aging, sex and risk factors stroke on regional cerebral blood flow (rCBF) in normal volunteers. Acta Neurol Scand 1979;suppl 72, 60:462-3.

26 Melamed E, Lavy S, Benton S, Cooper G, Rinot Y. Reduction in regional blood flow during normal aging in man. Stroke 1980;11:31-5.

27 Meric P, Luft A, Mamo H, Seylaz J. Evolution du débit sanguin cérébral en fonction de l'âge et des facteurs de risques vasculaires. Circulation et Métabolisme du Cerveau 1983;1:37-44.

28 Valmier J, Touchon J, Baldy-Moulinier M. Etude des débits sanguins cérébraux régionaux dans les épilepsies partielles complexes lésionnelles et non lésionnelles. Rev Electroencephalogr Neurophysiol Clin 1986;16:229-37.

29 Baldy-Moulinier M, Valmier J, Touchon J. Dominance hémisphèrique et foyer épileptique. Actes du $110^{\circ}$ congrès des Sociétés Savantes, Montpellier 1985, Sciences, Paris. CTHS 1985;iv:207-24.

30 Touchon J, Valmier J, Baldy-Moulinier M, Cadilhac J. Regional cerebral blood flow during interictal state: Differences between temporal lobe epilepsy and primary generalised epilepsy. Eur Neurol 1986;25:43-52.

31 McLachlan RS, Nicholson RL, Black S, Carr T, Blume WT.
Nuclear magnetic resonance imaging, a new approach to the investigation of refractory temporal lobe epilepsy. Epilepsia 1985;26:555-62.

32 Penfield W, Von Santha K, Cipriani A. Cerebral blood flow during induced epileptiform seizures in animal and man. J Neurophysiol 1939;2:257-67.

33 Plum F, Posner JB, Troy B. Cerebral metabolic and circulatory responses to induced convulsions in animals. Arch Neurol 1968;18:1-13.

34 Howse DC, Duffy TE, Plum F. Cerebral energy metabolism, pH and blood flow during seizures in the cat. Am J Physiol 1974;227:1444-51.

35 Engel J Jr, Kuhl DE, Phelps ME. Patterns of human local cerebral glucose metabolism during epileptic seizures. Science 1982;218:64-66.

36 Valmier J, Touchon J, Zanca M, Baldy-Moulinier M. Etude de la réactivité vasculaire cérébrale aux variations du gaz carbonique artériel dans l'épilepsie partielle complexe. Circulation et Métabolisme du Cerveau 1985;2:237-55.

37 Dasheiff R, Rosenbek J, Matthews C, Ramirez L. Epilepsy surgery improves regional glucose metabolism on PET scan [Abstract]. Epilepsia 1985;26:535. 